\title{
ENTRE O ESTADO E A REVOLUÇÃO*
}

\section{Cícero Araújo}

É típico de democratas que vivem em países governados por regimes autoritários uma fervorosa esperança de que um dia seus países atingirão o limiar da poliarquia. É típico de democratas que vivem em paises por longo tempo governados pela poliarquia uma crença de que a poliarquia é insuficientemente democrática e deveria tornar-se mais democrática.

(R. Dahl, 1989, p. 222).

$\mathrm{Na}$ onda recente de recuperação da chamada "tradição republicana", costuma-se tratar o ter-

* Este artigo é a versão condensada de seções de uma pesquisa mais extensa, ainda em elaboração. Partes do presente texto foram inseridas num outro trabalho de nossa autoria, a ser publicado na coletânea intitulada Teoria y Filosofía Política. La Recuperación de los Clássicos en el Debate Latinoamericano (A. Boron e A. de Vita (orgs.), Buenos Aires, Clacso, 2002). Agradecemos a Fapesp pelo apoio a esta pesquisa. mo democracia como se fosse um herdeiro natural de república. Supostamente intercambiáveis e derivados de uma mesma forma de pensar a política, eles são empregados para fazer um contraste com a "tradição liberal". O republican reviva, ${ }^{1}$ ademais, associa-se a um diagnóstico de crise das instituições tradicionais de representação (partidos, sindicatos), algo que, aliás, também vinha sendo tematizado por um pensamento liberal revigorado a partir da década de 1970. Ambos lançam um olhar bastante crítico à intromissão do Estado e das burocracias públicas, no decorrer do século $\mathrm{XX}$, em quase todos os aspectos da vida social. Porém, enquanto o liberalismo se preocupa com seus efeitos negativos na iniciativa privada ou individual, seus oponentes republicanos acentuam o entorpecimento do "viver civil" e a crescente indiferença da cidadania para com a res publica. Para esses últimos, resgatar as instituições de representação dessa crise implica resgatar 
ideais de participação que estariam implícitos no próprio fazer democrático.

Sem questionar outros laços que possam existir entre república e democracia, nosso objetivo neste artigo é registrar um distanciamento conceitual entre as combinações de ideais normativos que ambos encerram, e assim chamar a atenção para as dificuldades em fazer deles termos intercambiáveis. Salvo algumas exceções (duas das quais serão registradas no final deste trabalho), os autores que procuram resgatar o pensamento republicano dão pouca ou nenhuma atenção a essas dificuldades, por assumirem imediatamente a continuidade entre o que chamam "democracia" e o que chamam "república". E isso exige um exame crítico, até para que possamos dimensionar melhor o quanto a temática republicana clássica ainda pode nos ajudar a iluminar, e quem sabe renovar, o pensamento e a experiência democrática contemporânea.

Para fazer esse exame, vamos sugerir um contraste entre três diferentes ideais de cidadania. O primeiro, que chamaremos de civismo, é um ideal de excelência da participação do cidadão, que vamos tomar aqui como o campo de temas normativos privilegiado pela tradição republicana clássica, antiga e moderna $;^{2}$ o segundo, plebeísmo, é um ideal de universalização da participação; e o terceiro, pluralismo, é um ideal de tolerância para com diferentes, e às vezes contrários, estilos de vida e crenças religiosas e filosóficas dos cidadãos. Vamos considerar "democracia" um tipo de arranjo institucional que visa a esses três ideais. ${ }^{3}$ Todavia, como há tensões fundamentais entre plebeísmo e civismo ${ }^{4}$ - como procurarei mostrar aqui -, a democracia é, no plano normativo, a realização de um determinado equilíbrio entre eles, no qual o plebeísmo é o componente dinâmico e preponderante, enquanto o outro, embora indispensável, é um ideal subordinado. Para marcar o que é distintivo na democracia, vamos compará-la com três outros arranjos - a "República", a "Revolução" e o "Estado" - e sugerir afinidades e incompatibilidades entre esses e aquela, na medida em que possibilitem, ou não, o equilíbrio entre os três ideais.
I

Como estamos falando de ideais de cidadania, a entidade que consideramos fundamental neste trabalho é a civitas. A Civita é uma agência coletiva (a comunidade de cidadãos) que reinvidica autoridade sobre um espaço jurídico-moral que pode ser um território contínuo, mas não necessariamente - no qual estão situados os súditos. Este espaço é a jurisdição, e a autoridade da civitas sobre ele implica a obrigação de observar e priorizar suas decisões sobre as de qualquer outra agência concorrente. Como se pode ver, nem todos os que pertencem àquele espaço pertencem à civitas, mas todos os que estão na Civita (os cidadãos) são ao mesmo tempo súditos. A civitas também possui governo, que é uma agência que medeia as relações da civitas com seus próprios súditos e com as agências externas à sua jurisdição.

Nossa primeira tarefa é analisar como essa entidade e seu espaço de jurisdição transformamse quando o civismo e o plebeísmo interagem. O argumento central é que esses ideais podem se combinar para conformar arranjos institucionais estáveis, porém há uma tensão potencial entre exigir a excelência no exercício da cidadania e exigir a sua virtual universalização. Quando ocorre uma combinação de alta exigência de civismo e alta de plebeísmo, então a civitas desemboca na Revolução, que será considerado um arranjo volátil, instável, como vamos explicar daqui a pouco. Já a República e a Democracia são arranjos institucionais estáveis: na primeira, a combinação tem como elemento predominante ou dinâmico o civismo, e na segunda o elemento dinâmico é o plebeísmo. Mas quando o plebeísmo predomina, em detrimento do civismo, a civitas sofre outro tipo de transformação. Ela é, digamos assim, sublimada e no lugar dela (e falando em nome dela) deve aparecer o Estado, que pode ou não se mover na direção de um Estado democrático. Para que haja essa transformação, um ideal de tolerância, o pluralismo, deve aparecer quando o plebeísmo predomina, e pode até se tornar mais importante que o civismo. No entanto, quando há Estado democrático, o plebeísmo é sempre o elemento dinâmico fundamental, ao qual mesmo o pluralismo está subordinado. 
Para fazer a descrição básica e o cotejo dos arranjos República, Revolução, Estado e Democracia, vamos nos valer da tradição contratualista moderna, assim como da tradição do pensamento revolucionário. Os autores que vamos resgatar aqui pensaram em instituições para o mundo real, sem dúvida, mas, para tanto, todos eles tiveram de se orientar por idealizações de arranjos institucionais. São essas idealizações que vão nos interessar no argumento que segue.

Da tradição contratualista moderna, vamos tomar a concepção rousseauniana como uma justificativa do arranjo mais simples da República: o arranjo civitas/governo. ${ }^{5}$ Para Rousseau, o governo não é "nada senão uma comissão, uma função na qual, como simples servidores do soberano, exercem em seu nome o poder a eles confiado pelo soberano", o qual pode "limitar, modificar e tomar de volta quando quiser" (Rousseau, 1979, p. 79). Quem é o soberano? A comunidade de cidadãos, que é formada por um "ato de associação" que "produz um corpo coletivo e moral, composto de tantos membros quanto são as vozes na assembléia, a qual recebe deste mesmo ato sua unidade, sua identidade comum, sua vida e sua vontade" (Idem, p. 53, grifo do autor). É verdade que Rousseau, além de denominar essa associação "Cidade", "República" ou "Corpo Político", também a chama de "Estado". Mas "Estado" é uma entidade perfeitamente idêntica ao conjunto dos cidadãos, a diferença residindo apenas no fato de que esse conjunto se chama "Estado" quando "passivo", ao obedecer as leis, e "República" quando "ativo", ao fazer as leis. O que significa que todo cidadão é automaticamente um súdito da comunidade política, embora, como veremos, Rousseau esteja preparado para aceitar que muitos súditos não sejam cidadãos. Não há nada no Contrato Social que sugira a separação entre a noção de comunidade política e a de Estado. E, portanto, nada que sugira o conceito de Estado tal como o estamos empregando aqui.

A prova cabal disso é a tese da inalienabilidade da soberania da República. A soberania da comunidade dos cidadãos consiste numa "vontade", a "vontade geral", e como tal ela não pode ser transferida para nenhuma outra entidade. "O Poder pode perfeitamente ser transferido, mas não a vontade". Para Rousseau, o soberano é uni- camente um "ser coletivo" e, portanto, só pode ser representado por si mesmo, isto é, através da reunião de seus cidadãos, e não por um ato particular (Idem, p. 59). Como a vontade geral deve ser interpretada por atos particulares, estes últimos são necessariamente realizados por meio de uma instituição distinta, que é o "governo", o qual é o produto de uma transferência de poder, não de vontade. Essa distinção é fundamental para Rousseau. Pois quando a civitas transfere poder para uma mera "comissão" agir em seu nome, ela simplesmente está instruindo essa agência a fazer algo que ela não pode fazer coletivamente: o governo precisa existir porque o soberano não pode realizar atos particulares (Idem, p. 78). Mas um sinal definitivo de que está apenas transferindo poder, e não vontade, é que ela pode "limitar, modificar e tomar de volta" este poder no instante que quiser. Se não pudesse fazê-lo, em vez de transferir poder, estaria "alienando" a soberania.

Este é o argumento formal, puramente lógico. A idéia substantiva por trás deste argumento é a clássica rejeição republicana da divisão de trabalho entre cidadãos única ou principalmente dedicados à vida produtiva, ao trabalho e à aquisição material, e cidadãos dedicados exclusivamente à atividade política e à defesa da pátria. É isso que o faz rejeitar a idéia moderna de "representação". Assim, no mesmo capítulo em que afirma que a "soberania não pode ser representada pela mesma razão que não pode ser alienada", ele vai dizer que tal alienação vai ocorrer sempre que "o serviço público cessa de ser o principal assunto dos cidadãos, e eles preferem servir com seus bolsos e não com suas pessoas":

É necessário marchar para a batalha? Eles pagam tropas e permanecem em casa. É necessário atender à assembléia? Eles nomeiam deputados e permanecem em casa. Por força da preguiça e do dinheiro, eles finalmente têm soldados para escravizar o país e representantes para vendê-lo (Rousseau, 1979, pp. 101-102).

O ataque de Rousseau à representação, portanto, tem um significado muito mais importante do que a mera rejeição da eleição de delegados que falem em nome da civitas. Pois, na medida 
em que o conjunto dos cidadãos está sintonizado com os assuntos políticos comuns, esses delegados não passam de uma simples comissão, ou seja, "governo", o que é perfeitamente admissível na sua visão de soberania. O problema do moderno instituto da representação é que ela é o resultado, não da necessidade de governo, mas do cada vez maior envolvimento dos cidadãos "no comércio e nas artes, o ávido interesse em lucros... o amor aos confortos", o que leva à substituição "dos serviços em pessoa por dinheiro". E quando o cidadão deixa de colaborar pessoalmente na defesa da pátria e paga impostos para que militares profissionais o façam em seu lugar, ou deixa de "acorrer à assembléia" para que uma classe de políticos e burocratas administre o bem comum em seu lugar, o que ele está possibilitando é a edificação de uma entidade que pouco a pouco se separa da comunidade política e, no fim das contas, a submete, levando, na prática, ao seu desaparecimento.

Quando Rousseau rejeita a representação, no fundo está rejeitando aquilo que revolucionários como Marx e Lenin chamam de "Estado", e que é precisamente a noção de Estado que predominou no pensamento político moderno, como lembra Skinner. ${ }^{6}$ A forma institucional da república rousseauniana é, neste plano, idêntica àquela pensada por Marx durante a Comuna de 1871 e por Lenin em abril de 1917.

Porém, Rousseau e Marx têm visões muito diferentes a respeito dos participantes e das condições que possibilitam essa forma institucional. O pensamento de Rousseau é um exemplo de absoluta prioridade do civismo em relação ao plebeísmo. Em outras palavras, sempre que o plebeísmo parece colocar em risco a qualidade da cidadania, seu pensamento está perfeitamente preparado para restringi-la no nível que torne possível exigir de cada cidadão o cumprimento de seus deveres políticos. É por isso que Rousseau vai dizer que o melhor ambiente para materializar seu contrato social são pequenos territórios habitados por simples fazendeiros, dedicados a uma agricultura auto-suficiente e minimamente envolvidos com o comércio, produção de mercadorias e aquisição monetária. Pois territórios grandes e muito popu- losos, além de dificultar a reunião dos cidadãos, inevitavelmente requerem uma estrutura de funcionários permanentes e de impostos para pagálos, cujo peso crescente recai inteiramente sobre os súditos. E o enredar dos cidadãos no comércio, na indústria, nas finanças e mesmo numa vida exclusivamente urbana só tende a afastá-los de seus deveres políticos, induzindo-os a trocar, como vimos, sua "liberdade" (consubstanciada no exercício coletivo dos direitos políticos) por dinheiro.

As referências freqüentes aos hábitos cívicos de Roma e Esparta, as repúblicas exemplares da Antigüidade, e os de sua cidade natal, Genebra, a república moderna exemplar, mostram quão decisivo é para Rousseau a manutenção da severidade dos costumes para que a excelência da cidadania também seja preservada. Por outro lado, mostram também que ele está disposto a refletir sobre a realização do contrato social em condições abaixo das ideais. Pois ele sabe que nem Esparta, e muito menos Roma, satisfazem suas prescrições contrárias ao militarismo e à guerra de conquista que, ao levarem à expansão territorial e ao uso de escravos, tornam cada vez mais difícil manter o alto padrão da "virtude". Ele também sabe que boa parte da população de Genebra vive atarefada com o comércio. Mas ainda assim ele elogia a constituição dessas repúblicas por saberem, mesmo nessas condições adversas, ou "separar o joio do trigo", como em Esparta e Genebra, ao reconhecer plenos direitos políticos apenas a uma elite de cidadãos e negá-los aos habitantes mais propensos a corromper-se, ou, quando isso não é possível, como em Roma, ao providenciar certas distinções de status entre os próprios cidadãos, tornando um dos grupos (os patrícios) exemplo de espírito público para os demais. ${ }^{7}$

O essencial, para Rousseau, é que a República seja governada por um grupo de pessoas que estejam moralmente aptas e altamente desejosas de preservar sua própria liberdade. É este o objetivo supremo a ser conservado e que, em condições não-ideais, justifica o sacrifício da extensão da cidadania. Pois é melhor que aqueles com propensão a se furtarem de seus deveres cívicos, por conta de sua própria condição social - na época de Rousseau, mulheres, gente totalmente destituí- 
da, ou ainda certos tipos "proletários" e certos tipos "burgueses" -, sejam excluídos da comunidade de cidadãos, do que permitir que ela seja corrompida pelo seu ingresso. Acrescente-se a isso a necessidade de preservar um alto grau de consenso entre os cidadãos - pois quanto mais freqüente é a unanimidade, ou algo próximo a ela, maior é o sinal de que todos estão realmente atentos à consideração do bem comum (Rousseau, 1979, p. 108) -, o que é improvável quando vastos contingentes de todas as classes da população, geralmente muito heterogêneas e desiguais, são admitidas na civitas. Conseqüentemente, no arranjo institucional rousseauniano nada impede que uma minoria de cidadãos, que ao mesmo tempo faz e obedece as leis, governe uma maioria de súditos, que não faz as leis mas apenas as obedece. ${ }^{8}$

\section{II}

Marx certamente qualificaria as restrições à cidadania acima apontadas como preconceitos de classe, ou como expressões disfarçadas dos interesses das classes dirigentes. E sua teoria da revolução proletária é a maneira que ele encontrou para contornar as dificuldades de Rousseau em compatibilizar civismo e plebeísmo. A luta irreconciliável entre capitalistas e não-capitalistas é a cisão essencial das sociedades modernas, aquela que leva às desigualdades e aos conflitos mais relevantes e que impedem qualquer consenso real em seu interior. Uma vez eliminada essa cisão, estariam eliminadas também aquelas condições sociais que, no entender de Rousseau, impediam que largos segmentos da população adquirissem o privilégio de participar das decisões da comunidade política.

É verdade que Marx não pensou que todas as diferenças de classe pudessem ser eliminadas de uma hora para outra. Afinal, não existe apenas uma - os proletários urbanos, os trabalhadores assalariados - mas várias classes subjugadas pelos capitalistas. Mas, como ele diz no Manifesto Comunista, o próprio desenvolvimento do capitalismo na direção de oligopólios ou de virtuais monopólios nos diversos ramos de produção tornava es- sas classes aliadas "objetivas" do proletariado, o único capaz de oferecer-lhes uma alternativa digna, diferente da exploração e da pauperização. Ou seja: em vez de serem engolidas, a contragosto, pelo grande capitalista, elas deveriam, voluntariamente, aderir a um arranjo que pouco a pouco transformaria seus membros em novos contingentes de trabalhadores (Marx e Engels, 1986, pp. 491-492 e 494; Engels, s/d ). Eis porque, sob essas condições, todos os grupos subalternos da população, isto é, a imensa maioria, poderiam agora ser reconhecidos como cidadãos com plenos direitos políticos. Esse reconhecimento, aliás, deveria ser buscado antes mesmo da revolução proletária pois, como ele e seu amigo Engels sugeriram diversas vezes, dada a convergência "objetiva" de interesses, a extensão do sufrágio a todas as classes seria um passo importante, senão decisivo, para a conquista do socialismo (Marx e Engels, 1986, p. 504; Engels, s/d, pp. 26-30).

Contudo, os autores do Manifesto Comunista não oferecem argumentos específicos para convencer um rousseauniano de que tal universalização dos direitos políticos satisfaz igualmente a suas demandas de alto engajamento político. Ainda que fosse verdadeiro que, sem os capitalistas e sem a economia capitalista, a comunidade política estaria fadada a um consenso, graças à convergência de interesses materiais, isso ainda estaria longe dos requisitos de simplicidade, austeridade e lazer essenciais para uma cidadania ativa. Rousseau não está nem um pouco interessado no desenvolvimento das forças produtivas, no progresso material e tecnológico e coisas do tipo, pois a seu ver esses fenômenos levam as pessoas a enredar-se cada vez mais profundamente no círculo infernal da vida econômica, seja ela na forma da acumulação de riqueza ou na do consumo. Quanto mais homo oeconomicus eles são, menos bomo politicus podem ser.

O problema crucial é que Marx considera, ao contrário, ser indispensável uma alta participação política dos trabalhadores e, ao mesmo tempo, o contínuo, cada vez mais acelerado, desenvolvimento das forças produtivas, o que não pode ser feito sem uma intensificação da divisão de trabalho (Marx, vol. 6, p. 504). E ele não dei- 
xa claro como esses dois movimentos simultâneos poderiam ocorrer.

Essa tensão entre a participação política e a divisão do trabalho explica em parte por que a civitas revolucionária tende a ser uma agência instável. O problema crucial, contudo, é que, no início do processo revolucionário, a participação na comunidade política é acompanhada pela exigência de alto engajamento político, tal como Rousseau a prescreveu - isto é, um alto grau de civismo. Mas também é acompanhada pela exigência de ampla expansão de seus membros, vale dizer, um alto grau de plebeísmo. O primeiro requer um elevadíssimo nível de consenso da civitas e de uma forte convergência para com um mesmo objeto de interesses e atividades, enquanto o segundo leva a uma profunda diferenciação interna da comunidade e uma enorme divergência de objetos de interesses e atividades. E não se pode esperar um equilíbrio duradouro dessas duas tendências contrárias enquanto suas intensidades permanecerem tão elevadas, como na situação revolucionária. Conseqüentemente, tal como o estado de natureza hobbesiano acaba pressionando os indivíduos a aceitarem o Leviatã, a mistura explosiva de alto civismo e alto plebeísmo induz a revolução a romper gradualmente com o arranjo civitas/governo e a aceitar gradualmente a entidade estatal como representante, absoluta e irrevogável, do conjunto dos cidadãos.

A ascensão de uma entidade estatal, porém, não implica necessariamente que cada cidadão renuncie a qualquer engajamento político ou a qualquer direito de participação nas decisões políticas. Antes, ela pode significar um esforço dos próprios revolucionários para encontrar um patamar menos intenso de interação entre civismo e plebeísmo. E essa busca pode até resultar num arranjo que preserve os direitos políticos para praticamente todas as pessoas adultas e aceite não só níveis diferenciados de interesse dos cidadãos pela atividade política como a sua especialização. Tomarei tal arranjo como uma definição parcial de Estado democrático.

Contudo, é um tanto difícil que essa forma de Estado surja imediatamente de um processo revolucionário, embora isso possa ocorrer mais tar- de. O nascimento de uma civitas revolucionária abre um período de conflitos muito intensos, não só de interesses materiais, mas de valores morais, religiosos e filosóficos. Tais conflitos, mediados por canais institucionais em constante fluxo, alteram radical e continuamente a vida regular das pessoas, o que gera enorme insegurança. $O$ resultado é que, ao final do processo, a maioria dos cidadãos não só esgota quase por completo seu interesse por participar ativa e diretamente, como também está disposta a abrir mão de todos os seus direitos de participar, em troca de estabilidade. Hobbesianamente falando: o medo que inspira o aparato político que nasce dessa desistência, e que vai certamente monopolizar os meios de violência, e cujo uso pode ser inteiramente arbitrário, acaba sendo muito menor do que o medo que os cidadãos inspiram uns aos outros.

A dissolução da civitas revolucionária e a emergência de um novo Estado não significa que este último tenha de rejeitar as aspirações morais e políticas daquela. Isto pode acontecer apenas se ela for suprimida pelos inimigos declarados da revolução. Do contrário, é decisivo para a legitimidade do novo Estado que ele se aproprie daquelas aspirações. Pois a legitimidade do Estado consiste precisamente em ser capaz de se colocar no lugar da civitas e falar em nome dela, isto é, representá-la concretamente e idealmente.

Tal como a consolidação de um aparato estatal passa pela especialização e profissionalização da atividade política, a apropriação das aspirações morais e políticas da revolução requer uma formalização e depuração delas. Enquanto a civitas persiste, as aspirações revolucionárias circulam entre os cidadãos através de diferentes formulações filosóficas, muitas delas contraditórias entre si. Mesmo quando a civitas toma decisões que impliquem privilegiar momentaneamente uma formulação em detrimento de outras, isso ainda não significa o que estou chamando uma "apropriação", pois a vontade coletiva continua flutuante e descomprometida de uma formulação definitiva. É certo que os intelectuais revolucionários, que constituirão o núcleo do futuro aparato estatal, estão vivendo nessa fase uma feroz batalha ideológica - provavelmente organizados em diferentes "facções", "clubes" ou 
"partidos" - para definir qual o modo mais "correto" de formular e interpretar as aspirações da civitas. A ascensão da entidade estatal é concomitante à transformação dos fluidos ideais revolucionários numa versão oficial, numa doutrina que passa a orientar e sacramentar as deliberações dos que detêm o direito de tomar ou participar das decisões daquela entidade.

A doutrina oficial pode explicitamente reivindicar uma visão filosófica abrangente, e assim inserir a luta revolucionária numa missão histórica universal; quanto pode ser uma profissão de fé num conjunto mais ou menos rigoroso e coerente, mas paroquial, de princípios morais e jurídicos, que aponta e justifica a particularidade daquele Estado em relação à "comunidade dos Estados". Em ambos os casos, assim como a formulação da doutrina oficial é tarefa de intelectuais, também o será a de perpetuá-la e continuamente reinterpretá-la à luz das contingências do futuro. Esse trabalho de conservação da autoridade da doutrina oficial, que aos poucos vai gerando complexos procedimentos de exegese e interpretação, acaba se transformando numa atividade especializada no interior das instituições estatais ${ }^{9}$ - na forma, por exemplo, de um corpo de juízes encarregados de salvaguardar as "conquistas da revolução", as quais aparecem agora como leis supremas do Estado.

Em seu conjunto, essas leis supremas fornecem à entidade estatal uma ordem jurídica, em função da qual as decisões e as regras emanadas das instituições estatais deixam de aparecer como manifestações de uma vontade caprichosa, ${ }^{10}$ mas como emanações de um plano consistente e impessoal. E assim um emergente "Supremo Tribunal da Revolução" tende a reivindicar para si a autoridade para vetar decisões de outras instâncias estatais, se essas forem vistas como decisões que colocam em risco algum importante princípio revolucionário.

\section{III}

Em que sentido podemos falar de Estado democrático, então? Vamos destacar dois elementos que, apesar de não estabelecerem uma definição completa, fazem parte de seus atributos essenciais:
1) $O$ Estado democrático, como qualquer outro Estado, supõe a clara separação no interior da cidadania entre os que se dedicam exclusiva ou principalmente às atividades políticas - isto é, aquelas atividades cujo propósito último é estabelecer regras e tomar decisões que são compulsórias para o conjunto da população sob a autoridade daquele Estado - e os que se dedicam a qualquer outra atividade. Os primeiros são os funcionários públicos e os ativistas profissionais, e os segundos são os súditos.

2) No Estado democrático, as regras e as decisões estabelecidas pelos funcionários públicos são influenciadas, por meios legalmente reconhecidos (de modo explícito ou pelo silêncio da lei), por aproximadamente toda a população adulta dos súditos. Esses meios são os direitos políticos e os detentores da plenitude desses direitos ${ }^{11}$ - ou seja, os que os possuem em reconhecida igualdade com os demais - chamam-se cidadãos.

A primeira característica distingue o Estado democrático do arranjo simples civitas/governo, a República. A segunda característica não só distingue o Estado democrático da República, mas também de outras formas de Estado. Pois no Estado democrático os direitos políticos são reconhecidos para a parte mais extensa possível da população de súditos, com base num princípio normativo que é a melhor aproximação do ideal plebeísta compatível com a presença da entidade estatal. Esse ideal pode ser formulado da seguinte maneira: todos aqueles que estão sob a autoridade de uma agência que lhes dita decisões compulsórias têm o direito de participar dessas decisões. Num Estado democrático, essa participação se dá por meio de direitos políticos, isto é, dos meios de influência legalmente reconhecidos, os quais são estendidos igualmente aos súditos independentemente, a não ser num grau mínimo (como o limite inferior de idade e a exigência de nacionalidade), da qualidade moral ou da disposição cívica com que venham a exercê-los.

Essa desvinculação do direito de cidadania da excelência moral do seu exercício é o aspecto central da distinção entre o Estado democrático e 
a República. Pois, embora o Estado democrático preserve algumas exigências mínimas de qualificação - e é por isso que crianças, estrangeiros e mentalmente incapacitados são excluídos da participação -, tais exigências estão bem abaixo do engajamento cívico esperado e necessário para a sustentação da República. Por outro lado, a virtual universalização da cidadania também o separa de Estados onde a cidadania é o privilégio de uma pequena parcela da população, ou restrita apenas aos funcionários que tomam as decisões.

Vamos chamar a ação coletiva que agrega todos os cidadãos do Estado democrático de comunidade política secundária ou atual (o demos), para diferenciá-la da civitas, que é a comunidade política primária ou originária, ou seja, aquela que deve deixar de existir para que o Estado, inclusive o Estado democrático, possa emergir. A civitas, como vimos, envolve uma idealização da cidadania que não é compatível com a especialização e a profissionalização da política, enquanto o demos, ao reconhecer a autoridade de representantes e funcionários, o é. Em termos de regras e práticas institucionais, isso é perfeitamente compatível com os critérios da poliarquia de Dahl (Dahl, 1989, cap. 15).

Para a inteligibilidade da noção de Estado é crucial não só a distinção entre essa entidade e a civitas, mas também a idéia da transferência irrevogável da autoridade da última para o primeiro. Se a civitas continua a deter a última palavra nas decisões, independente de como as instituições estatais definam isso, então ela é soberana. Dizer, neste caso, que o Estado continua soberano é dizer que a civitas e o Estado são entidades idênticas, que é o que estamos procurando rejeitar aqui. Quando se afirma que a civitas jamais deixa de existir, mas apenas delega atribuições a uma entidade meramente administrativa, o que temos propriamente é uma civitas cum governo, e não a articulação de um "Estado". Isso significa que é a própria civitas que define quando e como recuperar a concessão feita ao governo. Mais do que isso: a recuperação é um ato de pura vontade, que não precisa submeter-se a uma regra previamente estipulada, pois esta pode ser alterada quando e como achar conveniente, desde que esteja reunida para tal.
Mesmo num Estado democrático, contudo, o demos não possui toda essa autonomia. Ainda que tenha poderes de eleger os agentes de governo, se legislativos ou executivos, e até de alterar leis por meio de plebiscitos e referendos, é certo que essas atribuições são rigorosamente delimitadas por uma ordem jurídica previamente estabelecida, o núcleo da qual - envolvendo o que poderíamos chamar de "questões constitucionais essenciais" - não pode ser alterado nem mesmo pelo demos, sem que os pilares daquele Estado desmoronem juntos. Essa ordem estipula, por exemplo, em que condições específicas o demos pode "reunir-se", que tipo de regra majoritária (se maioria simples, absoluta etc.) vale como uma "decisão" do demos e - mais importante ainda - a que instâncias um cidadão pode recorrer quando há uma disputa para saber se o procedimento que o demos utilizou para chegar a uma decisão foi corretamente observado, problema que geralmente escapa à alçada do próprio demos, e requer uma agência especializada, capaz de lidar com um conhecimento mais ou menos esotérico das leis fundamentais do Estado. Enfim, a existência de uma ordem jurídica prévia, que está acima da vontade do demos, é o que dá ao Estado democrático o seu caráter de Estado. ${ }^{12}$

Como essa ordem jurídica não pode ter surgido ex nibilo, estamos assumindo que tenha sido o legado de um indivíduo ou uma agência coletiva. Quando se trata de uma agência coletiva, que é a hipótese adotada neste artigo, e o seu legado é uma ordem democrática, então precisamos fazer a distinção, acima referida, entre essa agência, que é a comunidade política originária (a civitas), e o demos com poderes legalmente reconhecidos de influenciar as decisões de governo. A existência de um demos que pode trocar o governo por meio de eleições, mas que se submete a uma ordem jurídica que reconhece estar acima de sua própria "vontade", torna plenamente visível a diferença entre o governo do Estado e o Estado propriamente dito. Um governo pode perder a confiança dos cidadãos que o elegeram, sem que necessariamente o Estado perca sua legitimidade. Num Estado democrático, a mudança de governos pode ocorrer com bastante freqüência, sem que esse fato caracterize o que venho tratando 
neste trabalho como uma situação revolucionária. Contudo, quando a comunidade política passa a reclamar para si o poder, digamos assim, de "zerar" a ordem jurídica, de modificá-la como um todo, então, por esse gesto mesmo, ela está desafiando a autoridade, não do governo, mas do Estado. E, ao fazê-lo, deixa de ser um demos com específicas atribuições constitucionais, e que depende do suporte e da sanção de instituições estatais para existir, e assume a condição de uma nova civitas.

Para uma definição normativa completa do Estado democrático, mais dois elementos ainda são necessários: trata-se de um Estado que encarna uma certa visão do bem comum, e a prática reconhecida dessa visão, e um ideal de pluralismo. A primeira é uma sobrevivência do civismo. Só que, em vez de existir através da concentração prática dos cidadãos num mesmo campo de interesses, cuja prova é a participação na civitas, o bem comum é agora sublimado na ordem jurídica do Estado. Por certo, o Estado democrático não é a expressão de qualquer ordem jurídica, mas apenas daquela que é compatível com o reconhecimento de iguais direitos políticos a virtualmente toda a população adulta do território sob sua jurisdição. Muitas ordens jurídicas específicas são, porém, compatíveis com essa exigência geral. Por fim, o bem comum também deve estar expresso nas variadas justificativas filosófico-morais que essa prática recebe dos cidadãos e dos servidores do Estado, por meio de seus discursos públicos. ${ }^{13}$

Um Estado democrático supõe uma comunidade de cidadãos a mais extensa e heterogênea possível. A heterogeneidade existe não só pela possibilidade de vários tipos de desigualdades, consideradas compatíveis com o reconhecimento de iguais direitos políticos, mas também da dispersão da cidadania em diferentes objetos de interesse, além de distintas, e não raro contraditórias, concepções filosóficas, morais e religiosas, e divergentes estilos de vida. Em especial, a própria existência de um Estado implica o reconhecimento de uma região separada do espaço social, na qual um grupo destacado de cidadãos dedica mais sua atenção e esforço às atividades políticas do que os demais. Implica, portanto, que o restante da cidadania dedique uma proporção maior de suas energias a outras regiões do espaço social que não aquelas em que as atividades propriamente políticas estão concentradas. O conjunto dessas outras regiões é a sociedade civil. Estado e sociedade civil são, portanto, noções correlatas e fenômenos sociais complementares: a existência da segunda requer e remete à existência do primeiro.

\section{IV}

Algumas reflexões recentes (e outras nem tanto) sobre o problema de "aprofundar" as democracias têm manifestado um renovado ceticismo não só para com a via da Revolução, mas também para com a via do Estado. Por isso, elas acabam retornando à idéia da iniciativa direta e espontânea dos cidadãos, como uma espécie de terceira via. Certos defensores dela, plenamente cônscios da distância, teórica e prática, entre a República e a Democracia, procuram todavia apropriar-se de alguns anseios do republican revival contemporâneo através, por exemplo, da discussão sobre "sociedade civil". Mas ao trazer reminiscências, mesmo quando vagas, do ideal revolucionário e de seus percalços, ela vai exigir um trabalho de redefinição de conceitos. Gostaríamos de examinar esse esforço e submetê-lo à crítica, tomando as contribuições de dois autores.

Ambos pensam em modelos normativos para aprofundar a democracia em que, em vez de a República e a Revolução excluirem a via do Estado, como tem sido o enfoque do presente trabalho, as duas vias se combinam e se complementam. Não se trata de Estado ou Revolução, Estado ou República, mas Estado $e$ Revolução, Estado $e$ República. Evidentemente, pelo menos dois reparos às tradições revolucionária e republicana têm de ser feitos para que isso seja teoricamente possível. Primeiro, há de se fazer uma assimilação seletiva e crítica da Revolução: há revoluções desejáveis e indesejáveis. Segundo, há de se pensar uma civitas (que recebe outros nomes nos autores que vamos analisar) que coexista com o Estado, em vez de repudiá-lo.

$\mathrm{Na}$ primeira posição, o Estado e a civitas preenchem funções constitucionais distintas, cada qual cumprindo tarefas que a outra não pode, iso- 
ladamente, resolver. Um fascinante exemplo dela é a recente e intensa incursão de J. Habermas no campo da teoria democrática (Habermas, 1996). Reconhecendo seus débitos para com o pensamento político de $\mathrm{H}$. Arendt, Habermas procura assimilar as reflexões da última sobre a Revolução em seus conceitos de "poder comunicativo" e "esfera pública política”. Por outro lado, o Estado é compreendido pelas lentes da teoria sociológica contemporânea, especialmente a teoria funcionalista (Parsons) e a dos sistemas (Luhmann), e traduzido pelos termos "sistema político" e "poder administrativo". A política opera, então, em dois níveis que o próprio autor reconhece ser muito divergentes, mas que, de alguma forma, podem e precisam interagir positivamente. O elo perdido, e reencontrado, é fornecido pelos conceitos de "lei" e "direito".

Mas não é necessário expor aqui como Habermas reúne todas essas peças. Queremos apenas mostrar como a civitas e a Revolução insinuam-se na teoria, ainda que de forma bem represada, por meio do poder comunicativo e da esfera pública. Como em seu modelo normativo o Estado é desejável, é inevitável que o autor tenha de lidar com uma noção de "sociedade civil" que o complemente. Sociedade civil e Estado, porém, não correspondem a uma divisão do espaço social entre o público e o privado ou, melhor ainda, entre o político e o privado. Pois tanto o político quanto o privado podem ter regiões "colonizadas" por "sistemas" - que constituem funções, códigos e aparatos especializados: Estado, empresas capitalistas, mídia impressa e eletrônica - e outras regiões não colonizadas, que são manifestações do "mundo da vida", largadas à espontaneidade e à independência dos atores sociais. A região do político e do privado não colonizadas corresponde à sociedade civil: "A sociedade civil é composta daquelas emergentes associações, organizações e movimentos mais ou menos espontâneos que, sintonizadas com os problemas societais que ressoam nas esferas da vida privada, destilam e transmitem tais reações de forma amplificada à esfera pública” (Habermas, 1996, p. 367). A esfera pública, por sua vez, é "uma estrutura de comunicação enraizada no mundo da vida através da rede associativa da sociedade civil". Em especial, a "es- fera política pública" é uma espécie de "caixa de ressonância para problemas que devem ser processados pelo sistema político", "um sistema de alerta com sensores que, embora não especializados, são sensíveis ao longo de toda a sociedade" (Idem, p. 359). O aspecto espontâneo e a estrutura de comunicação da esfera pública lhe possibilitam gerar um tipo de poder político, o "poder comunicativo", aliás o poder político por excelência, já que é a fonte de todos os outros poderes políticos, inclusive o "poder administrativo" do Estado. É neste ponto que o autor tem como fonte o ideal de revolução de Arendt. O poder comunicativo é concebido como um poder político

[...] com força de autorização expressa na jurisgenesis - a criação de lei legítima - e na fundação de instituições [...]. Ele emerge na forma mais pura naqueles momentos em que revolucionários capturam o poder espalhado nas ruas; quando uma população comprometida com a resistência passiva opõe tanques estrangeiros com suas próprias mãos; [...] quando a pura "alegria da ação" irrompe em movimentos de protesto (Habermas, 1996, p. 148, grifo do autor).

Habermas, porém, sabe que o poder político pensado por Arendt não pode nem deve encontrar uma forma de acoplamento com as estruturas próprias do Estado. Em Arendt, o Estado é o resultado do vazio de "autoridade" da política moderna - vazio que não pode ser preenchido senão por essa forma de pura violência organizada - e, portanto, a antítese de sua concepção de "poder político" (Arendt, 1990, pp. 91 e 159-165): embora uma entidade de realidade histórica inegável, ela a rejeita inteiramente do ponto de vista filosófico-moral. Habermas, ao contrário, pensa que as sociedades modernas são muito complexas para dispensarem um sistema político especializado cuja base é o aparato administrativo do Estado: trata-se de uma entidade tão real quanto positivamente necessária. Assim, "a política não pode coincidir, como um todo, com a prática daqueles que conversam um com outro a fim de agir de um modo politicamente autônomo". O exercício do poder político "implica a formação discursiva de uma vontade comum", mas "não a implementação das leis dali emanadas". Em seu sentido pleno, o 
conceito do político "também inclui o uso de poder administrativo dentro do sistema político, assim como a competição pelo acesso àquele sistema" (Idem, p. 150, grifo do autor). De algum modo, o poder comunicativo tem de ser convertido em poder administrativo, e de tal forma que cada qual acabe respeitando suas dinâmicas específicas.

$\mathrm{Na}$ medida em que envolve uma "vontade comum" espontânea e autonôma capaz de gerar poder político, a esfera pública política habermasiana aproxima-se do que chamamos aqui de $\mathrm{ci}$ vitas. Mas, como os argumentos ao longo deste trabalho procuraram mostrar, a tentativa de reconciliação dessa última com o Estado deve colocar sua teoria num equilíbrio conceitual muito precário: não vemos como cidadãos colocados num lado do espaço social podem ser capazes de assumir uma posição de autoridade política fundacional e, ao mesmo tempo, admitir do outro lado que funcionários estabeleçam "decisões vinculantes". Como uma questão de fato, o Estado e a civitas podem muito bem ter existido e existir simultaneamente por algum tempo; o chamado "poder dual", típico das situações revolucionárias, atesta-o de modo inequívoco; o que é conceitualmente problemático é sua coexistência do ponto de vista normativo: a primeira entidade sempre quer, e precisa, se afirmar às expensas da outra, e vice-versa. Por outro lado, "Estado" e "sociedade civil" são compatíveis e podem coexistir estavelmente na exata medida em que a segunda é isto: sociedade civil, e não civitas. É claro que podem surgir de seu interior associações políticas voluntárias e não profissionais, "movimentos sociais" e "de protesto". Pode haver tudo isso sem que haja a reivindicação da jurisgenesis, ou sem que se pretenda deslocar a autoridade soberana do Estado.

De qualquer forma, a relação ambígua de Arendt no que diz respeito à experiência revolucionária - seu famoso On revolution sugere uma distinção normativa entre revoluções desejáveis, as revoluções dos "conselhos", feitas por uma elite de autênticos "cidadãos", e revoluções indesejáveis, fadadas à violência e ao terror, feitas pelas "massas" (cf. Arendt, 1990, pp. 255-281) - inspira Habermas a conceber as manifestações espontâneas da esfera pública como espécies de revoluções bem comportadas, capazes de se autolimitarem e permitir espaço suficiente para que o sistema político cumpra o seu papel. De modo que, se por um lado o "poder administrativo não deve se reproduzir em seus próprios termos", cabendo "regenerarse a partir do poder comunicativo", por outro, essa conversão deve ser suave o bastante para evitar que a esfera pública "arrebente o código de poder ao interferir no mecanismo autodirigido do sistema administrativo". Para tanto, "movimentos democráticos que emergem da sociedade civil devem abrir mão de aspirações holísticas por uma sociedade auto-organizada" e deixar-se embeber por uma "cultura política liberal e os padrões de socialização correspondentes". A sociedade civil, enfim, só pode "transformar diretamente a si mesma, e no máximo pode ter um efeito indireto na autotransformação do sistema político [...] de modo algum ela ocupa a posição de um macrosujeito que supostamente coloca a sociedade como um todo sob controle e simultaneamente age por ela" (Habermas, 1996, pp. 150 e 372, grifo do autor).

Mas ainda que a esfera pública política venha a encontrar um modus vivendi com o sistema político, a primeira tem de arranjar um modo de injetar sua agenda no segundo. Não se pode esperar, como o próprio Habermas admite, que o sistema político venha a fazê-lo de modo cooperativo e por sua própria iniciativa. A iniciativa, direta e espontânea, necessariamente tem de partir da sociedade civil politizada. É por isso, supomos, que Habermas acabe tendo de falar em "lutas", "ações sensacionais", "protestos de massa" e "movimentos de desobediência civil", o que caracteriza algo como uma latente quebra de braço entre os dois lados. O autor admite, contudo, como "empiricamente" implausível, que a sociedade civil - por sua "menor complexidade organizacional" e "mais frágil capacidade de ação" - seja capaz de continuamente reunir energias suficientes para alterar a rotina do poder administrativo. Essa constatação leva o autor a distinguir situações "normais", em que o sistema político tende a fazer prevalecer seu próprio ciclo "autoprogramado", e situações "críticas", excepcionais, em que os atores da esfera pública encontram uma chance de "reverter os circuitos normais de comunicação" entre um e outra e então assumir 
"um papel surpreendentemente ativo e momentoso" (Habermas, 1996, pp. 380-384).

Até onde precisamente esse papel ativo e momentoso pode ir, compatível com as tarefas de produzir "decisões vinculantes" atribuídas ao sistema político, isto é, compatíveis com a manutenção da autoridade do Estado de reclamar para si a sanção de tais decisões, Habermas não deixa nem um pouco claro. Porém, é interessante e significativo que ele acabe tendo de reconhecer que sua esfera pública política normalmente está desativada e apenas ocasionalmente, em situações bastante excepcionais, irrompa a cena política de forma vigorosa e irreverente, ainda que advertida para cumprir o script habermasiano de permanecer comedida.

Este desdobramento da visão habermasiana leva-nos para a segunda contribuição que mencionamos acima. Em vez de pensar em funções constitucionais distintas e complementares entre Estado e civitas, esta posição admite explicitamente um choque de funções entre ambos, não só como uma questão "empírica" (como é o caso de Habermas), mas como uma questão eminentemente conceitual. Neste caso, a coexistência entre as duas identidades, assim como o aprofundamento da democracia, só é plausível se a civitas nascer e renascer de tempos em tempos, provocar uma explosiva crise política e colocar sua pauta "revolucionária" a um Estado suficientemente poroso para aceitar uma reforma espetacular de seus princípios constitucionais. Essa posição pode ser ilustrada pela interpretação que B. Ackerman oferece para a história constitucional americana.

Ackerman pensa o Estado americano como uma "democracia dualista", na qual é possível distinguir dois tipos radicalmente distintos de decisões: uma feita "pelo Povo americano" e outra "por seu governo". Por um lado,

[...] decisões pelo Povo ocorrem raramente, e sob condições constitucionais especiais. Antes de ganhar a autoridade para fazer a lei suprema em nome do Povo, militantes políticos de um movimento devem, primeiro, convencer um extraordinário número de seus concidadãos para tomar sua pretendida iniciativa com uma seriedade que eles normalmente não dão à política; segundo, devem permitir a seus oponentes uma razoável oportuni- dade para organizar suas próprias forças; terceiro, devem convencer uma maioria de seus compatriotas a apoiar sua iniciativa enquanto seus méritos são discutidos (Ackerman, 1991, pp. 5-6).

Por outro lado, "decisões feitas pelo governo ocorrem diariamente, e também sob condições especiais. Acima de tudo, funcionários em posições centrais devem ser regularmente responsabilizados perante as urnas". Mas mesmo

[...] quando este sistema de "legislação normal" está operando bem, a Constituição dualista impede políticos eleitos de exagerar sua autoridade. Eles não podem reivindicar que uma vitória eleitoral lhes dê um mandato para criar um estatuto ordinário que coloque de lado os refletidos julgamentos a que o Povo chegou previamente" (Idem, ibidem).

Ackerman vê três grandes momentos da história americana em que "O Povo" abandonou a legislação normal e decidiu-se por escalar a íngreme colina da bigher law-making. Primeiro, nos anos de 1780, quando os Founders quebraram a dinâmica centrada nos Estados do Congresso Continental, mas deixaram irresoluto o problema da prioridade entre Estados e União; segundo, nos anos de 1860, quando os Reconstructers resolveram esse problema, deixando claro que a cidadania primária é nacional, não estadual, mas mantendo a inviolabilidade das questões econômicas e sociais; terceiro, nos anos de 1930, quando o New Deal estendeu os poderes da Constituição para este terreno (Idem, p. 105). Embora, no caso dos Estados Unidos, o texto constitucional não tenha sido explicitamente repudiado, mas apenas emendado, cada novo momento representou de fato uma "ruptura" com assunções prévias a respeito da interpretação do texto. Na visão de Ackerman, porém, a ruptura nunca foi um retorno à estaca zero, mas um verdadeiro salto à frente. Daí seu otimismo com relação a futuras rupturas, cujo desafio é continuar aprofundando as conquistas passadas: "o desafio é construir uma ordem constitucional que é mais justa e livre do que a que herdamos" (Idem, p. 5).

O autor usa o termo "revolução" para caracterizar essas rupturas. Todo período revolucioná- 
rio é seguido por um período de normalização, no qual as "conquistas" obtidas na ruptura são consolidadas na forma de emendas constitucionais ou de uma leitura inteiramente diferente do texto ancestral. O processo legislativo pelos representantes do Povo, certamente, não é interrompido, mas é submetido a uma vigilância pela "lei mais alta" emergida da intervenção direta do Povo. Daí que leis promulgadas pelos representantes do Povo podem ser repelidas por leis derivadas de um envolvimento supostamente mais profundo do próprio Povo. Quem fará essa vigilância? Na democracia dualista de Ackerman, um corpo especial do Estado pode muito bem se encarregar desta tarefa: "Em vez de ameaçar a democracia ao frustrar as demandas estatutárias da elite política em Washington, os tribunais servem a democracia ao proteger os princípios duramente conquistados por uma cidadania mobilizada contra sua erosão por elites políticas" (Idem, p. 10).

Como também carrega um sentido cognitivo, a la Kubn, já que cada período revolucionário marca uma virada no modo de entender a Constituição, ela não precisa implicar o sentido político de Revolução. Porém, a intenção do autor é precisamente enfatizar o sentido político. E ele o faz resgatando, como Habermas, as reflexões de Arendt a respeito: há de se "recuperar o significado político de revolução: o modo com que homens e mulheres podem revigorar sua identidade de cidadãos ao convocarem uns aos outros a marcar um 'novo começo' em sua vida política juntos". E, como Arendt, há de se recuperar esse significado sem sucumbir à tentação de "usar a experiência revolucionária [francesa] de 1789-1815 como um modelo contra o qual medir a experiência americana de 1776-1789". Se o fizermos "perderemos de vista que a Constituição americana foi entendida por seus participantes como o cume, ao invés de negação, de sua experiência política como revolucionários" (Idem, p. 210). Porém, contra Arendt, ele não vê por que um autêntico movimento revolucionário deveria deixar de lado a "questão social". De Thomas Jefferson ao movimento dos direitos civis liderado por Luther King, "uma preocupação com a 'questão social' serviu como o principal motor para engajar a participação pública do povo americano" (Idem, p. 209).
Apesar desse reparo, Ackerman não deixa de fazer sua própria demarcação entre revoluções desejáveis e indesejáveis. As primeiras são aquelas que, embora carregando um programa de reformas econômicas e sociais profundas, não visam a uma "revolução total nas relações econômicas e sociais". De modo que, embora as viradas constitucionais tenham significado alterações drásticas nas relações de poder, a ordem estatal não sucumbiu junto:

\begin{abstract}
Especialmente durante a Reconstrução e o New Deal, as tensões tornaram-se tão grandes que fios preexistentes da tradição constitucional visivelmente começaram a desentranhar-se. Nesses momentos de crise constitucional, as regras de base mesmas tornaram-se objetos [...] de reforma revolucionária. Os contendores vislumbraram o precipício [...]. Mas em vez de mergulhar no caminho da revolução total, a resposta em ambos os momentos foi a reforma revolucionária (Idem, p. 211).
\end{abstract}

Como em Habermas, para que o Estado e a civitas possam coexistir, a Revolução tem de saber se autolimitar, e os revolucionários comportarem-se apropriadamente. Diferentemente de Habermas, porém, Ackerman não sente nenhum desconforto com o caráter ciclotímico da cidadania moderna, que entra, e só pode entrar, diretamente na cena política apenas em momentos bem espaçados.

Embora consideremos sua "visão dualista" da democracia essencialmente correta - seu The People corresponde aproximadamente ao que estamos chamando aqui de civitas - fazemos duas restrições à teoria de Ackerman:

1) Muitos historiadores e cientistas políticos hão de resistir à idealização da história constitucional americana oferecida pelo autor. Alguns vão considerar o processo que culminou na Constituição Federal de 1787, mesmo se tratando de uma "ruptura", mais como uma espécie de "reação termidoriana" do que uma "revolução". ${ }^{14}$ Outros vão certamente considerar que o processo iniciado com a guerra civil de 1861-1865 representou na prática uma "revolução total" no Sul, na medida em que destruiu impiedosamente, naquele território, a ordem aristocrática e as respectivas relações sociais e econômicas preexistentes. E outros ainda, talvez mais sobriamente, 
vão interpretar que a guerra civil foi, na verdade, não uma Revolução, mas uma guerra entre dois Estados - portanto, duas entidades com territórios distintos -, na qual o vencedor simplesmente impôs suas condições ao derrotado. As mudanças constitucionais ocorridas em seguida poderiam, portanto, ser vistas como o subproduto político de uma guerra estritamente conduzida por um Estado, e não como uma "Revolução dentro da ordem" promovida pelo Povo.

2) Não nos parece plausível supor que a abrupta democratização da civitas, que é a Revolução, venha a conservar sua harmonia interna, a ponto de conseguir, quase por unanimidade, "reprogramar" o Estado. Ao contrário, há de se esperar não só, num primeiro momento, o "poder dual" - no qual, ou a autoridade do Estado, ou a autoridade da nova civitas, deverá prevalecer - mas também, num segundo momento, o crescimento vertiginoso de conflitos de toda sorte no interior do próprio Povo. E neste ponto não temos mais, simplesmente, a tensão entre duas entidades externas uma à outra (o "Povo" e o "Estado"), mas uma tensão crucial no interior da cidadania. Num Estado democrático, essa última tensão mantém-se administrável e conduzida segundo aquelas regras típicas, e acordadas, da competição política e da contestação civil. Contudo, a situação revolucionária é uma ruptura com regras prévias e transcorre em meio a um virtual vácuo jurídico e institucional. Rigorosamente falando, é difícil pensar em algo como uma "Revolução dentro da ordem", como sugere Ackerman, embora possamos até cruzar os dedos e esperar que tudo acabe bem. Mas a idéia é conceitualmente frágil.

A busca de um caminho intermediário entre o Estado e o "holismo" revolucionário, de qualquer forma, só confirma o magnetismo que o ideal da República continua a exercer sobre o pensamento democrático contemporâneo. Mesmo o ideal da Revolução não desaparece inteiramente. Submetido a crítica, ele reemerge mitigado e com outros nomes. Pois, para os autores que sinceramente defendem o caminho da democracia, mas experimentam com desilusão os percalços da via estatal de seu aprofundamento, a disposição para engajar-se numa empreitada como essa tem de estar disponível, apesar de todos os riscos que a própria crítica tratou de apontar.

É bastante natural que se contentem, porém, não com uma revolução "permanente", mas com o seu repetido nascimento, morte e renascimento. É que, apesar de sua frustração com a via do Estado, eles mesmos não vêem de que outra maneira a vida coletiva moderna poderia ser conservada. A iniciativa coletiva, direta e espontânea dos cidadãos - a "liberdade" no sentido arendtiano - é algo a ser desejado, mas como um instrumento, ou melhor, como um aríate contra os corredores corrompidos da representação estatal, que não deve ser dispensada, mas recauchutada. Por outro lado, esses mesmos autores admitem, mais ou menos como pensavam certos "espontaneístas" da velha tradição revolucionária, que o tempo da República, embora esperado, jamais pode ser planejado. A existência mesma de um Estado e de uma sociedade civil revela que os cidadãos não estão concentrados num mesmo objeto de interesses, nem estão dispostos a aceitar a qualquer momento os trajes gregos do zoon politikon. Num certo período, apenas alguns estão concentrados e a maior parte não; em outros, ninguém está realmente preocupado com isso, a não ser os profissionais de sempre; e ainda em outros, muitos estão preocupados, mas isso não leva necessariamente aos compromissos de engajamento que a República requer, tal como a coragem para colocar muita coisa pessoal em risCo, no limite a própria vida, a favor de uma empreitada política. A República exige, portanto, uma convergência de atenções e disposições a um só tempo rara e fortuita.

Como pensar, contudo, que esse movimento ciclotímico venha a "aprofundar" a democracia? A idéia de aprofundamento implica a de um aperfeiçoamento: um acréscimo, uma acumulação, uma melhora, contínua ou periódica, da qualidade das instituições democráticas. Não se trata de colocar em dúvida, aqui, se pode ou não haver essa acumulação. O ponto de interrogação diz respeito a condicionar o aprofundamento aos "ciclos" revolucionário-republicanos. Pois, se a visão esboçada neste artigo faz sentido, o ressurgimento da civitas coloca a política não na rota da acumulação, mas na do ridurre ai principii maquiaveliano. As- 
sim, a experimentação de tais ciclos acaba, na prática, não preservando, mas deslocando o Estado, e, portanto, a representação, do centro da atividade política: é difícil imaginar como os dois poderiam "progredir" ao mesmo tempo. E, porém, a democracia, se estamos corretos, implica um compromisso umbilical com o Estado e a representação.

Se alguém disser, todavia, que a ação não-representada dos cidadãos é o modo por excelência de melhorar a qualidade da própria representação democrática, então teremos de admitir que essa melhora só é possível não com a intensificação, mas com a diminuição do papel dessa última. $\mathrm{E}$ isso tem como conseqüências práticas, entre outras, concentrar a idéia de aprofundamento ou na pura e simples conclamação à "vida ativa", à espera de que um dia ela venha a encontrar ampla ressonância; ou numa estratégia educacional para criar, nos futuros cidadãos, um hábito que torne possível a estabilização desse modo de vida, pois se trataria então de modificar as instituições modificando a conduta pessoal. Inclinamo-nos a pensar, entretanto, que a experiência democrática gera, a partir da combinação de ideais de cidadania que lhe é peculiar, uma expectativa um tanto distinta dessa, e, portanto, os anseios de seu aprofundamento, supondo que venham a encontrar vazão no futuro, devem pender para outra direção, cujo terreno, aliás, já nos é bastante familiar. Ou seja, para os modos com que, cada vez mais, diferentes parcelas da população poderiam ter suas demandas mais bem carreadas para as agências estatais, e seus conflitos mútuos melhor mediados, por meio de velhos e novos institutos de representação. Por certo, também nessa direção os bloqueios são formidáveis, como numerosas análises sobre o assunto apontam há um bom tempo, mas parece-nos mais de acordo com o papel dominante que o plebeísmo exerce nas democracias contemporâneas.

\section{NOTAS}

1 C. Sunstein (1988).

2 A fronteira de temas e autores dessa tradição, porém, dificilmente pode ser delineada com precisão. Os autores que normalmente são colocados nessa longa linhagem de pensamento (Aristóteles, Políbio, Cícero, Maquiavel, J. Harrington, J. J. Rousseau, T. Jefferson, H. Arendt e tantos outros) mais compartilham de certas questões comuns - entre as quais a da "excelência" ou "boa qualidade" da cidadania do que respostas convergentes a elas. Fala-se, neste sentido, de diferenças internas à própria tradição; por exemplo - se seguirmos a sugestão de Taylor (1985) - entre o "republicanismo clássico", propriamente, e o "humanismo cívico". Mas não vamos nos concentrar nelas neste artigo. Por fim, é possível identificar autores - J. S. Mill, para ficar num caso notório - que lidam tanto com preocupações mais diretamente filiadas à tradição liberal, quanto com preocupações tipicamente republicanas.

3 Estamos supondo que as instituições democráticas reais carregam consigo tais ideais, os quais dão origem a um campo de forças normativas que as movimentam. Certamente as forças normativas não são as únicas que movem as instituições, e talvez nem sejam as mais intensas. As motivações econômicas e geopolíticas, por exemplo, geram, cada qual à sua maneira, campos de força provavelmente bem mais intensos que as normativas. A presente análise vai restringir-se, porém, a essas últimas. Pensamos que, mesmo se fossem realmente de intensidade mais fraca, seus efeitos de longo prazo seriam de qualquer modo decisivos para a conservação dos tipos de arranjos institucionais que examinaremos.

4 Há também tensões entre esses dois e o pluralismo. Porém, vamos nos ater ao contraste entre plebeísmo e civismo.

5 O arranjo mais complexo é a "constituição mista", que analisamos em outra oportunidade. Ver C. Araújo (2000, pp. 11-22).

6 "A despeito da indubitável importância desses teóricos republicanos clássicos [ele está se referindo ao primeiros republicanos modernos, renascentistas, a utilizarem o termo 'Estado'], entretanto, ainda seria enganoso concluir que seu uso do termo stato e seus equivalentes expressa nosso conceito moderno de Estado. Este conceito veio a incorporar um caráter duplamente impessoal. Nós distinguimos a autoridade do Estado da dos governantes ou magistrados [...]. Mas nós também distinguimos sua autoridade da de toda sociedade ou comunidade sobre a qual seus poderes são exercidos [...]. Os teóricos republicanos abraçam apenas metade desta noção duplamente abstrata. Por um lado não há dúvida, penso eu, que eles constituem o grupo [moderno] mais remoto de escritores políticos que insistem com toda consciência numa distinção categorial entre o Estado e aqueles que o controlam [...]. Mas por outro lado eles não fazem nenhuma distinção comparável entre os poderes do Estado e os de seus cidadãos. Ao contrá- 
rio, todo o peso da teoria republicana clássica é colocado numa equação última entre os dois" (Q. Skinner, 1989, p. 112).

7 A república romana pode ser considerada um caso histórico do ideal de "constituição mista" no qual, mesmo havendo uma ampla extensão, para os padrões da Antigüidade Clássica, do direito de votar (mais ampla do que a democracia ateniense, por exemplo), o peso individual desse direito era diferenciado de acordo com a "centúria" ou a "tribo" a que o cidadão pertencia. Por outro lado, as barreiras para ocupar postos de governo, entre os que possuíam direito de votar, eram bem maiores do que as da experiência ateniense (cf. W. Eder, 1991, pp. 174 ss.).

8 Para um argumento - sem dúvida controverso nessa direção, ver D. Rosenfeld (1987).

9 A especialização, na forma do Estado, de uma região "política", não exclui uma ulterior especialização interna das próprias atividades políticas.

10 Assim como o predomínio da vontade direta do "Povo" é um empecilho à plena consolidação do Estado, também o é o predomínio da vontade pura de um indivíduo.

11 Os direitos políticos incluem não só o direito de votar (ou de ser representado), mas o direito de se expressar e de se associar (ou de representar outros). O voto como forma de decisão invoca um princípio majoritário. A justificativa do princípio majoritário, porém, dificilmente pode prescindir de um ideal de bem comum e de consenso, derivado do civismo, o qual deve permanecer acima das divergências que levam à contagem dos votos. Ver as observações de R. Dahl em A preface to democratic theory, 1956, cap. 2.

12 Nossa posição, aqui, é próxima da visão constitucionalista de B. Ackerman (1991), com sua separação entre a "política constitucional", que é atributo do People, e a "política ordinária", que é atributo dos eleitores e seus representantes. Voltaremos a Ackerman no final deste artigo.

13 Deixamos a prospeção sobre a base argumentativa comum que essas justificações devem possuir, e a intrincada questão de como ela pode se combinar com o ideal do pluralismo, para uma outra oportunidade.

14 "Todas as noções de um corpo político foram desafiadas ao longo dos anos de 1780 por um ascendente movimento entre as altas classes sociais e os interesses econômicos mais poderosos. Ele produziu a Constituição, com sua diferente concepção [em relação aos tempos da Confederação] de coletividade e poder [...]. A nova Constituição visou reverter a direção do país, estabelecê-la contra a política democrática e participatória florescendo nos Estados" (S. Wolin, 1981, p. 13).

\section{BIBLIOGRAFIA}

ACKERMAN, B. (1991), We the people: foundations. Cambridge, Mass., Belknap Press.

ARAUJO, C. (2000), "República e democracia". Lua Nova, 51: 5-30.

ARENDT, H. (1990), On revolution. Londres, Penguin Books.

DAHL, R. (1989), Democracy and its critics. New Haven, Yale University Press.

(1956), A preface to democratic theory. Chicago, Chicago University Press.

EDER, W. (1991), "Who rules? Power and participation in Athens and Rome", in A. Molho, K. Raaflaub \& J. Emlen. (orgs.), City States in classical antiquity and medieval Italy, Ann Arbor, The University of Michigan Press.

ENGELS, F. (s/d), "Introduction", in Marx, K., The class struggles in France (1848-50), Londres, Martin Lawrence.

HABERMAS, J. (1996), Between facts and norms. Cambridge, Mass., MIT Press.

MARX, K. \& ENGELS, F. (1986), Collected works. Nova York, International Pubs., vols. 6 e 22.

ROSENFELD, D. (1987), "Rousseau's unanimous contract and the doctrine of popular sovereignty". History of Political Thought, VIII (1): 83-109.

ROUSSEAU, J-J. (1979), On the social contract. Nova York, St. Martin's Press.

SKINNER, Q. (1989), "The State", in J. Farr, T. Ball \& R. L. Hanson (eds.), Political innovation and conceptual change, Cambridge, Cambridge University Press.

SUNSTEIN, C. (1988), "Beyond the republican revival". Yale Law Journal, 97: 1539-1590.

TAYLOR, C. (1985), Philosophical papers. Cambridge, Cambridge University Press, vol. 2.

WOLIN, S. (1981), "The people's two bodies". Democracy, 1 (1): 9-24. 


\section{ENTRE O ESTADO E A REVOLUÇÃO}

Cícero Araújo

\section{Palavras-chave}

Teoria democrática; Republicanismo; Estado; Sociedade civil; Revolução

Sem questionar todos os outros laços que possam existir entre República e democracia, é nosso intento neste artigo registrar um distanciamento conceitual entre as combinações de ideais normativos que ambos encerram, e assim chamar a atenção para as dificuldades em fazer deles termos intercambiáveis. Salvo algumas exceções (duas das quais serão registradas no final deste trabalho), os autores que procuram resgatar $\mathrm{O}$ pensamento republicano dão pouca ou nenhuma atenção para essas dificuldades, por assumirem imediatamente a continuidade entre o que chamam "democracia" e o que chamam "república". E isso exige um exame crítico, até para que possamos dimensionar melhor o quanto a temática republicana clássica ainda pode nos ajudar a iluminar, e quem sabe renovar, o pensamento e a experiência democrática contemporânea.

\section{BETWEEN THE STATE AND THE REVOLUTION}

Cícero Araújo

\section{Keywords}

Democratic theory; Republicanism; State; Civil society; Revolution

Notwithstanding all other possible links between Republic and Democracy, the intent of this article is to point out a conceptual gap between the combinations of normative ideals related to those two institutional arrangements, therefore highlighting the difficulties of making them interchangeable terms. Apart from a few exceptions (two of them being subject of our analysis here), the authors who try to rescue the Republican tradition of political thought pay almost no attention to those difficulties, assuming immediately the continuity from what they call "Democracy" to what they call "Republic". This requires a critical examination in order to better access how the typical topics of the classical Republicanism can still help us to illuminate, and even innovate, the contemporary democratic thought and experience.

\section{ENTRE L'ÉTAT ET LA RÉVOLUTION}

\author{
Cícero Araújo
}

\section{Mots-clés}

Théorie démocratique; Républicanisme; État; Société civile; Révolution

Sans remettre en question tous les autres liens qui puissent exister entre la République et la démocratie, nous nous proposons, dans cet article, de faire un registre de l'écart conceptuel entre les associations d'idéaux normatifs que ces deux notions englobent. Nous attirerons, ainsi, l'attention vers les difficultés d'en faire des termes interchangeants. À quelques exceptions près (deux desquelles apparaîtront à la fin de ce travail), les auteurs qui cherchent à récupérer la pensée républicaine, accordent peu ou aucune importance à ces difficultés, car ils assument immédiatement la continuité entre ce qu'ils appellent de "démocratie" et ce qu'ils appellent de "république", et ceci qui exige un examen critique, jusqu'à ce qu'on puisse mieux évaluer combien la thématique républicaine classique peut encore nous aider à éclairer et, pourquoi pas, renouveler - la pensée et l'expérience démocratique contemporaine. 